\title{
Infertility Information System with an approach to Data Architecture: A Systematic Review
}

\author{
Somayeh Sadat Seyedi, Azamossadat Hosseini, Reza Rabiei, Farkhondeh Asadi and Hamid \\ Moghaddasi* \\ Department of Health Information Technology and Management, School of Allied Medical Sciences, Shahid Beheshti University of Medical sciences, Tehran, \\ IRAN. \\ *Corresponding author: Hamid Moghaddasi, Associate professor of Health Information Management \& Medical Informatics, \\ Department of Health Information Technology and Management, School of Allied Medical Sciences, Shahid Beheshti University of \\ Medical Sciences, Tehran, IRAN. Email: Moghaddasi@sbmu.ac.ir
}

To Cite This Article: Hamid Moghaddasi. Infertility Information System with an approach to Data Architecture: A Systematic Review. Am J Biomed Sci \& Res. 2019 - 5(4). AJBSR.MS.ID.000922. DOI: 10.34297/AJBSR.2019.05.000922.

Received: 眥 September 09, 2019; Published: 眥 September 27, 2019

\begin{abstract}
Infertility is one of the major healthcare problems around the world. In order to provide infertile couples with appropriate services, it is essential to have an integrated information system for the management of infertility data. One of the most important aspects of this system is its data architecture so that relevant data can be properly managed and made available to users.

The aim of this study was to determine data architecture components in infertility information systems including data sources, organizations involved in infertility care, data exchanges and datasets.

In this systematic review the four databases (PubMed, Scopus, Science Direct, and Embase) searched. Studies related to each of the various stages of designing, creating, and developing information systems and registries for infertility and assisted reproductive technology were selected. These articles were those published in English between 2007 and 2018.

Findings resulting from 44 selected articles were categorized into four groups including data sources, organizations involved in infertility care, data exchanges, and datasets. The most important data sources are databases, paper forms, patient and birth registries, and vital records. Organizations involved in data management include producing and coordinating organizations. The main data exchanges took place between infertility clinics and national infertility databases.

Provision of proper services to infertile couples requires a well-designed information system, which collects relevant information from different sources, and makes it available to relevant individuals. Data in this system are used to effectively treat infertility, assess the success rates and safety of assisted reproductive technology, and allocate resources.
\end{abstract}

Keywords: Infertility; Data Architecture; Infertility Information System; Infertility Information System Architecture

\section{Introduction}

Infertility is one of the major healthcare problems in all societies around the world [1], and it is one of the most important medical and social problems affecting the mental health of families and societies [2]. According to reports, the world's infertility rate has risen by $50 \%$ since 1955 [3]. In general, infertility is defined as the inability to achieve a pregnancy after 12 months of regular unprotected sexual intercourse [4-7] for most people, and six months in cases where the woman is older than 35 years of age [8], in a way that the couple are not able to achieve a pregnancy after a year of trying [6]. The United States National Institutes of Health (NIH) has provided the above definition as well, and states that the term "infertility" is also used to refer to women who are able to become pregnant, but who cannot maintain the embryo until the end of pregnancy [9]. Infertility occurs both in women and in men $[4,10]$.
According to the United States National Infertility Association, one couple out of every eight couples at reproductive age, $12.5 \%$ of the population at reproductive age) faces the problem of achieving a pregnancy or finishing the pregnancy period $[11,12]$. The average prevalence of infertility is $3.5 \%$ to $16.7 \%$ in developed countries, and $6.9 \%$ to $9.3 \%$ in developing countries [1].

Effective design and implementation of relevant programs and protocols by competent infertility-related organizations and entities play a valuable role in infertility management; that is, they organize health services and reduce costs [13]. The Centers for Disease Control and Prevention (CDC) in the United States have released a plan titled "The National Public Health Action Plan", whose content reflects the scope of programs and activities run by the CDC in relation to infertility management. The aim of this plan is to discover, 
prevent, and manage infertility [14]. In the United Kingdom, the Human Fertilization and Embryology Authority (HFEA) is responsible for the treatment of infertility. This organization is responsible for collecting data about assisted reproductive technology (ART), stored in a database called the "HFEA Register" [15].

The above-mentioned countries and other countries that have infertility management plans have employed information systems to effective and efficient management of infertility. Information systems can provide information regarding more precise assessment of infertility in society, as well as the safety and effectiveness of treatments. These systems can collect information from sources such as donors of egg, sperms, and embryos, patients treated through specific fertilization methods, and cancer patients who use fertility preservation techniques [16]. With increasing infertility globally, the importance of infertility information systems becomes further highlighted. Such a system can help health authorities, medical professionals, and laboratory experts provide patients with optimal care. It can also give the general public a better understanding and view of ART [17]. One of the appropriate methods for comparing pieces of infertility information is the establishment of an information system to collect comprehensive data from all centers that carry out ART [18]. Due to the increasing growth of infertility data and information and importance of managing data and information collected about ART, an information system is needed to collect, control, and regulate these therapeutic cycles in terms of reducing potential risks [19] because the analysis of the probability of success in the treatment of infertility is influenced by the complete and valid data which are made available. For instance, the efficacy of ART is shown by data related to the usefulness and safety of such methods. Data related to treatment methods and their outcomes are important and interesting to all stakeholders including patients, health planners, inspectors, and centers for assisted repro- duction [20]. In order to provide infertile couples with appropriate services, it is essential to have an information system because such a system allows for sharing experiences between different centers, and helps define the best dimensions of treatment to improve the outcomes of ART. In addition, in order to provide infertility plans, it is important to exchange information about the accessibility, efficacy, and safety of ART. Therefore, all stakeholders can enhance the advantages of such developing techniques [21].

This study was conducted with the aim of determining the main components of infertility information systems with an approach to data architecture in order to provide a basis for the production and implementation of an efficient infertility information system.

\section{Materials and Methods}

Electronic sources were searched based on MeSh and Emtree terms in the title, abstract, and keywords of articles published in English.

Searches were conducted in the databases such as PubMed, Scopus, Science Direct, and Embase within a time interval from 2007 to 2018. Figure 1 shows the search strategy for finding relevant articles. Part I (A) contains infertility-related terms, and Part II (B) contains terms related to information systems. In Figure 1, MeSH and Emtree terms appear bolder than other terms. With these two parts combined, the search query was formed: ("Infertility" or "Reproductive Sterility" or "Sterility" or "Sterility, Reproductive" or "Sub-Fertility" or "Subfertility" or "Assisted Reproductive Technology") and ("Information Systems" or "Registry" or "Data Source" or "Database" or "Information architecture" or "Data architecture" or "Information architecture modeling" or "Information system architecture" or "Information system architecture modeling" or "infertility data interchange" or "infertility data exchange" or "infertility data sharing" or "infertility data interoperable" or "data standard")

\section{Infertility \\ 2. Reproductive Sterility \\ 3. Sterility \\ 4. Sterility, Reproductive \\ 5. Sub-Fertility \\ 6. Subfertility \\ 7. Assisted Reproductive Technology \\ 8.1 or 2 or $\sim$ or 7}

\section{A}

1. Information Systems
2. Registry
3. Data Source
4. Database
5. Data standard
6. Information architecture
7. Data architecture
8. Information architecture modeling
9. Information system architecture
10. Information system architecture modeling
11. Infertility data interchange
12. Infertility data exchange
13. Infertility data sharing
14. Infertility interoperable data
15. 1 or 2 or or 14

B

Search query: A.8 and B.15

Figure 1: Key words, Emtree and MeSH terms (bold terms) used in the search strategy. 
The complementary search continued through reviewing the list of references in the selected articles, and after reading the full text, an article was added to the existing articles. When reviewing the full text of articles, studies related to each of the various stages of designing, launching, creating, developing, and analyzing the results of processing data available in information systems and/or networks of databases and registries for infertility and assisted reproductive technology (at the regional, national, and international levels) were selected. At this stage, no relevant studies were found at the Cochrane database. Out of the articles from other databases, studies that were necessarily about software production and assessment, data mining analysis and/or bioinformatics topics were excluded from the screening process. The search procedure and results are shown in Chart 2. At the stage of completing the select- ed articles, a deeper study of the full texts was conducted to gain a further understanding of the description of the place of each component of the data architecture in an infertility information system as well as how each of them works in the system. Different types of databases and registries, how they are related to different types of organizations responsible for supervising, owning, and managing infertility and ART databases, data sources, datasets, and data standards were analyzed. At the data extraction stage, the results of this analysis were adjusted and completed in the form of content lists and tables as well as their detail classification tables.

\section{Results}

44 articles were selected out of the 2,490 records found, after the screening process (Figure 2). The reviewed studies had been conducted between the years 2007 to 2018.

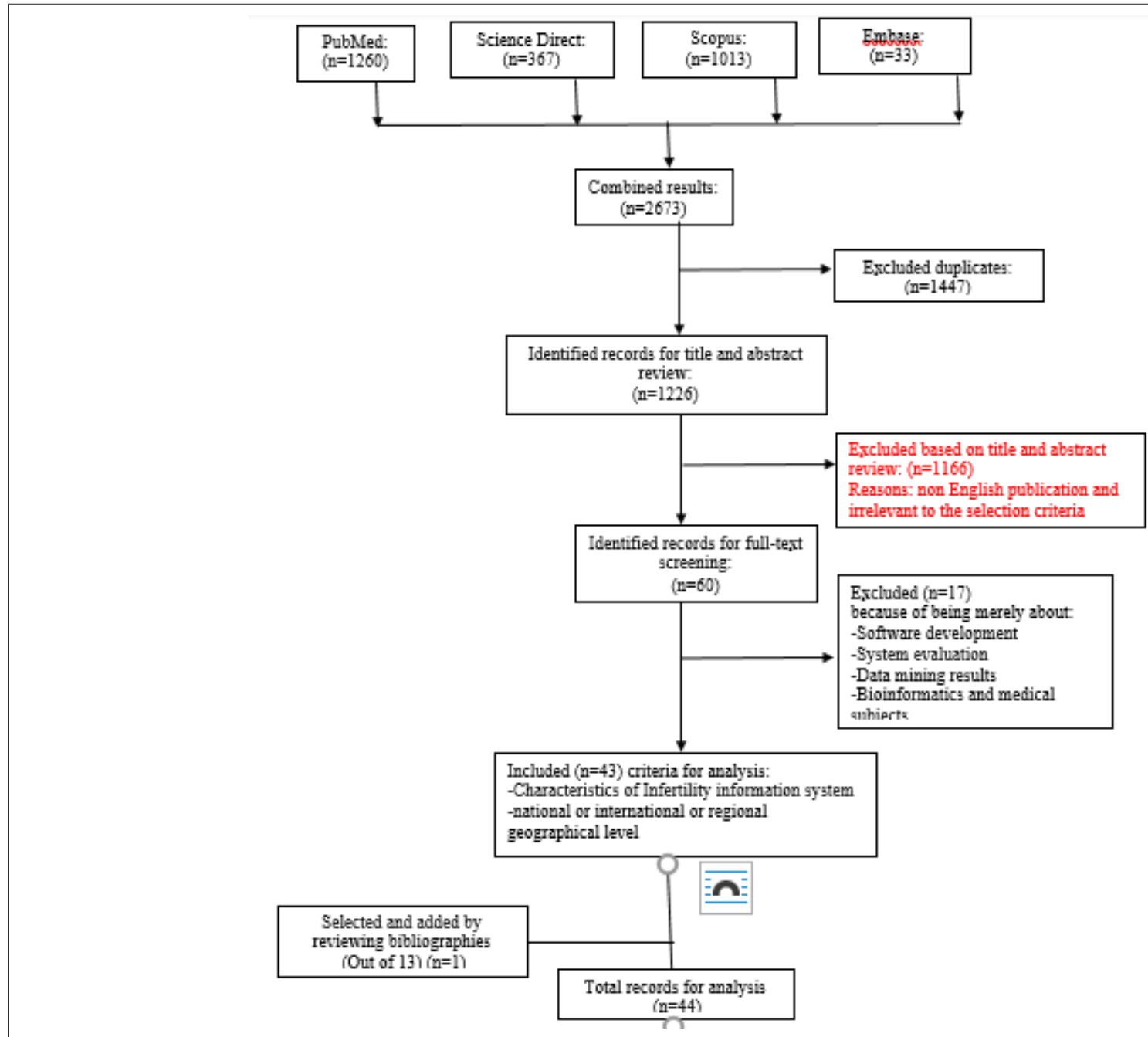

Figure 2: Search Flow Diagram.

The largest number of studies with 12 cases (27.27\%) belonged to Europe. Only three cases (6.81\%) out of the studies belonged to African countries, one case belonged to Australia, and eight cases out of the studies were conducted at the international level (Table 1).
After reviewing the full texts of articles included in the study and categorizing the findings, finally, the data architecture components of infertility information systems were divided into five groups: the data sources of databases, the institutional ownership of databases, data exchanges, datasets, and data standards (Table 2). 
Table 1: Distribution of articles according to geographical origin.

\begin{tabular}{|c|c|c|}
\hline Geographical Origin of Study & Frequency of records (percentage of 44 included studies) & Reference Number \\
\hline $\begin{array}{c}\text { European Region (Denmark, Spain, Belgium, Swiss, } \\
\text { Germany) }\end{array}$ & $12(27.27 \%)$ & {$[18,23,27,30,41,46,52-57]$} \\
\hline United States & $11(25 \%)$ & {$[22,25,26,58-65]$} \\
\hline Asia (Iran, Japan, Thailand, china (Beijin), India) & $9(20.45 \%)$ & {$[17,20,21,28,29,31,32,45,47]$} \\
\hline Africa (South Africa, Egypt) & $3(6.81 \%)$ & {$[24,35,37]$} \\
\hline Australia & $1(2.27 \%)$ & {$[46]$} \\
\hline
\end{tabular}

Table 2: Infertility Information System Characteristics.

\begin{tabular}{|c|c|c|}
\hline Characteristics & Frequency of records (percentage of 44 included studies) & Reference Number \\
\hline Data source & $14(\% 31.81)$ & {$[21-32,35,37,41,47]$} \\
\hline Involved organization & $17(\% 38.63)$ & {$[18,21,23-32,41,59-62]$} \\
\hline Data exchange & $35(\% 79.54)$ & {$[18,22-36,44,38-41,51-65]$} \\
\hline Dataset & $43(\% 97.72)$ & {$[18,21,24,29,33-41,44-47,51-58-65,33,34,36,38-40,49,51-57]$} \\
\hline Data Standard & $22(\% 50)$ &
\end{tabular}

\section{Data Sources}

Based on studies conducted, databases of infertility information systems can be supplied with data from various sources including databases of clinics and infertility centers; and these data can be in paper or electronic forms [22-29]. Some infertility clinics like those in Belgium use web-based systems [30] to report their data; and some others, like those in Japan, use online registration systems [31,32]. Each infertility database uses multiple data sources (Table 3). categorizes a summary of these data sources. The

Table 3: Common data sources in Infertility Information System.

\begin{tabular}{|c|c|c|}
\hline Table 3: Common data sources in Infertility Information System. & \multicolumn{2}{|c|}{ Reference Number } \\
\hline Data Source & Frequency of records (percentage of 44 included studies) & {$[22-24,27-29,44]$} \\
\hline Clinics (electronic forms) & $7(\% 15.90)$ & {$[21,35,37,41,47]$} \\
\hline Clinics (paper-based forms) & $5(\% 11.36)$ & {$[25,27]$} \\
\hline $\begin{array}{c}\text { Other registries (Patient Register, Birth Register, disease } \\
\text { registry) and Records (Stateś Vital records) }\end{array}$ & $2(\% 4.54)$ & \\
\hline
\end{tabular}

\section{Organizations Involved in Data Management}

\begin{tabular}{|c|c|c|c|}
\hline Country & Organization name & $\begin{array}{l}\text { Frequency of records (percentage } \\
\text { of } 44 \text { included studies) }\end{array}$ & $\begin{array}{l}\text { Reference } \\
\text { number }\end{array}$ \\
\hline USA & Division of Reproductive Health (DRH) & $1(\% 2.27)$ & [25] \\
\hline Canada & IVF Directors Group of the CFAS & $4(\% 9.09)$ & [58-61] \\
\hline Denmark & National Board of Health (DNBH) & $1(\% 2.27)$ & [27] \\
\hline Spain (Catalonia) & Spanish Fertility Society (Sociedad Española de Fertilidad; SEF) & $1(\% 2.27)$ & [18] \\
\hline Belgium & Belgian Register for Assisted Procreation (Belrap) & $1(\% 2.27)$ & [30] \\
\hline Swiss & Swiss Society of Reproductive Medicine (SGRM) & $1(\% 2.27)$ & [41] \\
\hline South Africa & $\begin{array}{l}\text { African Society of Reproductive Medicine and Gynecological Endosco- } \\
\text { py (SASREG) }\end{array}$ & $1(\% 2.27)$ & [24] \\
\hline Thailand & Reproductive Medicine Subcommittee (RMS) & $1(\% 2.27)$ & [28] \\
\hline Japan & Japan Society of Obstetrics and Gynecology (JSOG) & $2(\% 4.54)$ & {$[31,32]$} \\
\hline $\begin{array}{l}\text { Australia and New } \\
\text { zealand }\end{array}$ & Fertility Society of Australia (FSA) & $1(\% 2.27)$ & [44] \\
\hline India & Indian Society of Assisted Reproduction (ISAR) & $1(\% 2.27)$ & {$[21]$} \\
\hline china (Beijin) & $\begin{array}{l}\text { Beijing Human Assisted Reproductive Technology Centre for Quality } \\
\text { Control and Improvement }\end{array}$ & $1(\% 2.27)$ & [29] \\
\hline
\end{tabular}

most important sources to receive information (in electronic and/ or paper reporting forms) are infertility clinics. In addition, these databases may receive information from other registries. Whereas, there are also some databases, whose data sources are other registries, and an example of which is the Danish IVF registry database, which receives its data from the Danish Medical Birth Register and the Danish National Patient Register in addition to electronic forms of infertility clinics [27]. Furthermore, in the United States, data from the National ART Surveillance System (NASS) are linked to the states' vital records and the disease registry [25]. 
Based on the conducted studies, there are national authorities in different countries that are responsible for managing and supervising infertility data sent from clinics, as well as for maintaining databases. Organizations involved in the infertility data management are classified into two groups: producing organizations (clinics) and coordinating and supervising organizations. The supervising organizations in the conducted studies were nonprofit [30] and/or state-owned organizations [18,21,22,25,26,29]. One of the most important coordinating and supervising organizations, based on the studies, was the Division of Reproductive Health (DRH) at the CDC [25]. Table 4 lists coordinating and supervising organizations referred to in the studies.

\section{Data Exchanges}

Based on the studies, data exchanges were performed between infertility clinics and the central infertility and ART database in 17 cases $(38.63 \%)$ out of the studies. From among the other data exchanges observed in two cases (54.4\%) out of the studies, were data exchanges between the infertility or ART registry and other registries and records (Table 5).

\begin{tabular}{|c|c|c|c|}
\hline Data exchange and communication & Data exchange direction & $\begin{array}{l}\text { Frequency of records (percent- } \\
\text { age of } 44 \text { included studies) }\end{array}$ & Reference number \\
\hline Clinics with central database (registry) & One-way & $21(\% 47.72)$ & $\begin{array}{c}{[18,21-32,35,37} \\
41,44,58-61]\end{array}$ \\
\hline $\begin{array}{c}\text { Central database (registry) with specific and local data- } \\
\text { bases (registries) }\end{array}$ & One-way & $13(\% 29.54)$ & $\begin{array}{c}{[27,33,34,36,38-40} \\
51-57]\end{array}$ \\
\hline
\end{tabular}

\section{Datasets and Data Standards}

Out of the 44 reviewed articles, all of them had addressed datasets and their relevant elements. The datasets are categorized into five main groups: demographic data, medical history, ART-related data, and data related to the outcomes and complications of these procedures (Table 6).

Data such as the results of laboratory and imaging procedures were also found in the studied databases. Some of the studies have also referred to data elements such as participating centers [23],

Table 6: Infertility Information System Characteristics.

\begin{tabular}{|c|c|c|}
\hline Data Set & $\begin{array}{c}\text { Frequency of records (percent- } \\
\text { age of 44 included studies) }\end{array}$ & Reference number \\
\hline Demographic data & $11(\% 25)$ & {$[20,25,29,31,32,46,47,58-61]$} \\
\hline Clinical data & $43(\% 97.72)$ & {$[17-32,33-41,44-47,51-65]$} \\
\hline Para clinical data & $2(\% 4.54)$ & {$[20,45]$} \\
\hline History (medical, surgery, infertility, obstetric and pregnancy, sexual) & $9(\% 20.45)$ & {$[20,25,27,45,47,58-61]$} \\
\hline Treatment outcomes (pregnancy and delivery) & $35(\% 79.54)$ & {$[18,21,22,23,25-41,44-47,51-61]$} \\
\hline Complications & $14(\% 31.81)$ & {$[29,33-40,46,51,58-61]$} \\
\hline
\end{tabular}

\section{Discussion}

In the second decade of the new millennium, infertility has still remained a very common situation across the world. The infertility rate reaches 30\% in some parts of the world including South Asia, Sub-Saharan Africa, the Middle East and North Africa, Eastern and Central Europe, and Central Asia [42]. Infertility is of great importance in western societies in a way that its average prevalence is estimated at $9 \%$ in these countries [43].

In developed European [18,23,27,30,50,52,54-59] and American $[22,25,26,32-39]$ countries, more attention has been paid to the issues of infertility and its treatment, as well as the creation and development of registries and databases in this domain. The present study classifies organizations involved in infertility data management into two groups: producing organizations and coordinating performed treatments [24, 33-40], and/or singleton and multiple-gestation pregnancies [33,34,36,38-41]. The number of transmitted embryos has also been mentioned in a number of studies $[23,24,30,33,34,36,38-40]$. Moreover, a study has referred to the number of canceled treatments [41].

Twenty-two cases (50\%) had referred to the use of standard terminologies in order to standardize infertility datasets. These cases are related to the use of a glossary on ART terminology published by the International Committee for Monitoring Assisted Reproductive Technology (ICMART).

organizations. It should be noted that the most important group among these organizations includes data-producing organizations into which infertility clinics fall. These organizations can be either governmental or non-governmental. Careful and continuous supervision by supervising organizations can have a significant effect on improving the performance of data-producing organizations. If correct, relevant, and high-quality data are generated by the group of producing companies, managerial levels can use these data to make and update appropriate policies in this regard.

Based on the findings of the present study, the data sources of an infertility information system are diverse. These sources put patients' clinical data at the disposal of the system. They mainly include electronic and/or paper forms, web-based systems, and/or online registration systems that contain main data about infertility 
and ART, and that are sent to the central infertility database through clinics [2,22-28,30-32,35,37,41). In addition to these essential data, an infertility information system can receive data from birth registries, patient registries [27], disease registries, and vital records [25]. Moreover, receiving follow-up data from medical records can help complete the information of infertility databases [44].

Due to the diversity of data sources in an infertility information system, it is very difficult to determine a dataset for such a system. Therefore, different datasets for infertility have been introduced in sources [20,45-47]. One type of categorization is the division of datasets into seven categories: main demographic data; treatment cycle characteristics; data on the type of drugs used; data on oocytes; fertility; and embryos; and treatment outcome (pregnancy and childbirth) and complication data [46]. Another category introduced in this regard divides the required data into two general categories: clinical and paraclinical data. Paraclinical data include data on couples' laboratory test results and couples' medical imaging results. Clinical data encompasses data on females' current disease history; females' reproductive system history; pregnancy history; females' sexual and infertility history; male's diseases and problems; males' case history; couples' previous medical and surgical history; couples' disease history; couples' consultations; and couples' treatments [45]. Another categorization divides these data into three main groups: the patient's main information, the previous medical history, and the treatment plan [47]. In another example of categorization, infertility data are divided into patients demographic data, their medical history, and the results of laboratory tests, diagnosis, and treatment [20]. Although all these categorizations include main data required for infertility management and treatment, some studies take into consideration the number of infertility centers and clinics [23], the number of treatments performed $[23,24,33-40]$, and the number of treatments canceled as well [41]. It is noteworthy that in all the studies, demographic data, and diagnostic and therapeutic data were taken into consideration, but that paraclinical data and data on medical history and treatment outcomes and complications were not reported in some studies. This is while the safety and success rates of ART can be assessed based on the results of these treatments. Due to the diversity of data sources and infertility data, efficient and effective use of these data requires the presence of an integrated information platform; and this integration is realizable in the light of using data standards.

Different types of standards affect the quality of data in different dimensions [48]. It is essential to have standard definitions in order to benchmark the ART results at the national and international levels. When data are collected internationally, standardization is necessary so that efficiency, safety, and quality of multinational actions and researches can be monitored [49].

In the present study, a standard terminology was introduced for the purpose of data exchanges. This standard terminology is based on a glossary on ART terminology published by the Interna- tional Committee for Monitoring Assisted Reproductive Technology (ICMART) and the World Health Organization (WHO) under the title "ICMART-World Health Organization (WHO) glossary" $[18,21,24,29,30,33,34,36,38-40,49,51-65]$. A standard terminology provides a common language that facilitates data exchanges between different registries and databases. Although other standards such as HL7 Messaging Standard are used to exchange health documents, this study has only addressed standard terminologies.

Data exchanges and how they flow at different levels are among the components of data architecture [50]. In the present study, infertility clinics transmit data requested from coordinating and monitoring organizations in different forms (electronic or paper forms, online registration systems) to central databases present in these organizations $[17,22-28,30-32,35,37,41]$. Another group of communications is data exchanges between the central database or registry and other specialized databases and registries such as the medical birth registry and the national patient registry [27]. Of course, it should be noted that the presence of a developed information system can integrate patients' information, improve the quality, safety, and accessibility of medical care services, reduce costs, and provide specialists with relevant and necessary information, and facilitate researches into the field of infertility through collecting comprehensive, complete, and integrated data. Due to the need for the collection of accurate data, as well as analysis and processing of these data, the presence of an infertility information system is essential for any country because an infertility information system can help better understand the effect of ART on infertile people.

\section{Conclusion}

The presence of an integrated information system is of great importance for effective and efficient infertility management. If this system can be produced and developed based on the principles of the architecture of information systems, infertility data management will improve. Clear data sources, use of standard datasets that facilitate data collection and processing, and use of messaging standards will result in appropriate responses to users' needs at different levels.

\section{Acknowledgements}

We declare that we have no conflict of interest. There is no financial support in this study.

\section{References}

1. Masoumi SZ, Parsa P, Darvish N, Mokhtari S, Yavangi M, et al. (2015) An epidemiologic survey on the causes of infertility in patients referred to infertility center in Fatemieh Hospital in Hamadan. Iran J Reprod Med 13(8): 513-516.

2. Akhondi MM, Kamali K, Ranjbar F, Shirzad M, Shafeghati S, et al. (2013) Prevalence of primary infertility in Iran in 2010. Iran J Public Health 42(12): 1398-1404

3. Dirkvond Moghaddam A, Delpisheh A, Sayeh Miri K (2014) Infertility rate in Iran by systematic review. IJOGI 16(81): 1-7.

4. (2015) Centers for Disease Control and Prevention, Reproductive Health. Infertility FAQ's. 
5. Lindsay Tj, Vitrikas KR (2015) Evaluation and Treatment of Infertility. American Family physician 91(5): 308-314.

6. (2014) American Society for Reproductive Medicine. Defining Infertility.

7. Seifoleslami M, Safari A, Khameneie MK (2015) Prevalence of Ureaplasma urealyticum and Mycoplasma hominis in High Vaginal Swab Samples of Infertile Females. IRCMJ 17(12): e16823.

8. (2015) Mayo Foundation for Medical Education and Research. Infertility.

9. (2013) US Department of Health and Human Services, National Institutes of Health. Infertility and Fertility: Condition Information.

10. (2015) United Healthcare Services, Inc. Infertility Diagnosis and Treatment.

11. (2015) The National Infertility Association (RESOLVE). About infertility

12. Ehdaei vand F, Majd Far Z, Nayebi M (2015)Deputy of Health of Shahid Beheshti University of Medical Sciences, Deputy of Health Affairs, Healthy Breastfeeding Unit and Population. Identification and referral of infertile couples in the health system based on leadership guidelines.

13. Osman A (2011) Management of infertility within primary health care program in Sudan. Asian Journal of Scientific Research 4(2): 158-64.

14. (2016) Centers for Disease Control and Prevention (CDC). CDC Programs and Activities.

15. (2013) Human Fertilisation and Embryology Authority (HFEA). Fertility treatment in 2013-trends and figures. UK: Human Fertilisation and Embryology Authority (HFEA).

16. (2014) Centers for Disease Control and Prevention (CDC). National public health action plan for the detection, prevention, and management of infertility. Atlanta, Georgia: Centers for Disease Control and Prevention.

17. Abedini M, Ghaheri A, Samani RO (2016) Assisted reproductive technology in Iran: the first national report on centers, 2011. Int J Fertil Steril 10(3): 283-289.

18. Bosser R, Gispert R, Torné M, Calaf J (2009) Status of human assisted reproduction in Spain: results from the new registry of Catalonia. Reproductive BioMedicine Online 19(5): 727-733.

19. Gillain N, Bogaerts K, Albert A, Guillaume M, Lesaffre E (2015) A webbased support system of the Belgian Register for Assisted Procreation.

20. Abbasi M, Ahmadian L, Amirian M, Tabesh H, Eslami S (2018) The Development of a Minimum Data Set for an Infertility Registry. PHIM 15(Winter):1b-32b.

21. Malhotra N, Shah D, Pai R, Pai HD, Bankar M (2013) Assisted reproductive technology in India: A 3 year retrospective data analysis. J Hum Reprod Sci 6(4): 235-240

22. American Society for Reproductive Medicine (2007) Assisted reproductive technology in the United States: 2001 results generated from the American Society for Reproductive Medicine/Society for Assisted Reproductive Technology registry. Fertil Steril 87(6): 1253-1266.

23. Bühler K, Bals Pratsch M, Blumenauer V, Dahncke W, Felberbaum R, et al. (2012) DIR Annual 2011. J Gynakol Endokrinol (Journal of Reproductive Medicine and Endocrinology) 9(6): 453-484.

24. Dyer SJ, Kruger TF (2012) Assisted reproductive technology in South Af rica: first results generated from the South African Register of Assisted Reproductive Techniques. SAMJ 102(3): 167-170.

25. Mneimneh AS, Boulet SL, Sunderam S, Zhang Y, Jamieson DJ, et al. (2013) States Monitoring Assisted Reproductive Technology (SMART) Collaborative: data collection, linkage, dissemination, and use. J Womens Health (Larchmt) 22(7): 571-577.

26. Sunderam S, Kissin DM, Crawford SB, Folger SG, Jamieson DJ, et al. (2017) Assisted reproductive technology surveillance - united states, 2014. MMWR Surveillance Summaries 66(6): 1-24.
27. Tølbøll Blenstrup L, Knudsen LB (2011) Danish registers on aspects of reproduction. Scand J Public Health 39(7_suppl): 79-82.

28. Vutyavanich T, Piromlertamorn W, Ellis J (2011) Assisted reproductive technologies in Thailand: 2001-2007 results generated from the ART Registry, Royal Thai College of Obstetricians and Gynaecologists. TJOG 37(3): 236-244

29. Zhou Z, Chen L, Wu H, Zheng D, Li R, et al. (2018) Assisted reproductive technology in Beijing, 2013-2015. Reprod Biomed Online 37(5): 521532 .

30. De Neubourg D, Bogaerts K, Wyns C, Albert A, Camus M, et al. (2013) The history of Belgian assisted reproduction technology cycle registration and control: a case study in reducing the incidence of multiple pregnancy. Hum Reprod 28(10): 2709-2719.

31. Saito H, Jwa SC, Kuwahara A, Saito K, Ishikawa T, et al. (2017) Assisted reproductive technology in Japan: a summary report for 2015 by The Ethics Committee of The Japan Society of Obstetrics and Gynecology. Reprod Med Biol 17(1): 20-28.

32. Irahara M, Kuwahara A, Iwasa T, Ishikawa T, Ishihara O, et al. (2017) Assisted reproductive technology in Japan: a summary report of 19922014 by the Ethics Committee, Japan Society of Obstetrics and Gynecology. Reprod Med Biol 16(2): 126-132.

33. Dyer S, Chambers GM, De Mouzon J, Nygren KG, Zegers Hochschild F, et al. (2016) International committee for monitoring assisted reproductive technologies world report: Assisted reproductive technology 2008, 2009 and 2010. Hum Reprod 31(7): 1588-1609.

34. Ishihara O, Adamson GD, Dyer S, de Mouzon J, Nygren KG, et al. (2015) International Committee for Monitoring Assisted Reproductive Technologies: World Report on Assisted Reproductive Technologies, 2007. Fertil Steril 103(2): 402-413.e11.

35. Mansour R, El Faissal Y, Kamal O (2014) The Egyptian IVF registry report: Assisted reproductive technology in Egypt 2005. Middle East Fertil Soc J 19(1): 16-21.

36. Mansour R, Ishihara O, Adamson GD, Dyer S, de Mouzon J, et al. (2014) International Committee for Monitoring Assisted Reproductive Technologies world report: assisted reproductive technology 2006. Hum Reprod 29(7): 1536-1551.

37. Mansour RT, Abou Setta AM, Kamal O (2011) Assisted reproductive technology in Egypt, 2003-2004: Results generated from the Egyptian IVF registry. Middle East Fertil Soc J 16(1): 1-6.

38. Nygren KG, Sullivan E, Zegers Hochschild F, Mansour R, Ishihara O, et al. (2011) International Committee for Monitoring Assisted Reproductive Technology (ICMART) world report: assisted reproductive technology 2003. Fertil Steril 95(7): 2209-2222.

39. Sullivan EA, Zegers Hochschild F, Mansour R, Ishihara O, De Mouzon J, et al. (2013) International Committee for Monitoring Assisted Reproductive Technologies (ICMART) world report: Assisted reproductive technology 2004. Hum Reprod 28(5): 1375-1390.

40.Zegers Hochschild F, Mansour R, Ishihara O, Adamson GD, de Mouzon J, et al. (2014) International Committee for Monitoring Assisted Reproductive Technology: world report on assisted reproductive technology, 2005. Fertil Steril 101(2): 366-378.

41. De Geyter C, Fehr P, Moffat R, Gruber IM, von Wolff M (2015) Twenty years' experience with the Swiss data registry for assisted reproductive medicine: outcomes, key trends and recommendations for improved practice. Swiss Med Wkly 145(w14087): 1-13.

42. Inhorn MC, Patrizio P (2015) Infertility around the globe: new thinking on gender, reproductive technologies and global movements in the 21st century. Hum Reprod Update 21(4): 411-426.

43. Cardona D, Leite R, Carvalho A, Campos C, Coelho C, et al. (2014) Epidemiologic study of infertility: report of the hospital centre of St. John, Porto. REV INT ANDROL 12(4): 123-131. 
44. Macaldowie A, Wang YA, Chambers GM, Sullivan EA (2013) Assisted reproductive technology in Australia and New Zealand 2011 Sydney: National Perinatal Epidemiology and Statistics Unit, the University of New South Wales: The University of New South Wales, Australia.

45. Farzandipour M, Jeddi FR, Gilasi HR, Shirzadi D (2017) Clinical and Para Clinical Information Needs of Infertility Electronic Health Records in Iran: A Delphi Study. Acta Informatica Medica 25(3): 163-168.

46. Germond M, Wirthner D, Senn A (2008) Core data for assisted reproductive technology registers: results of a consensus meeting. Reproductive BioMedicine Online 17(6): 834-840.

47. Safdari R, Choobineh H, Rampisheh Z, Vahedi Barzoki A (2016) Analysis of infertility electronic registration system data elements a comparative study. Biomedical and Pharmacology Journal 9(1): 323-336.

48. Nahm M, Hammond WE (2013) Data standard $\neq$ data quality. Studies in health technology and informatics 192:1208.

49. Zegers Hochschild F, Adamson GD, de Mouzon J, Ishihara O, Mansour $\mathrm{R}$, et al. (2009) International Committee for Monitoring Assisted Reproductive Technology (ICMART) and the World Health Organization (WHO) revised glossary of ART terminology, 2009*. Fertil Steril 92(5): $1520-1524$

50. Bridget Derc GC (2011) Review Of Information Architecture In: intelligence $\mathrm{cfw}$, editor

51. Adamson G David, de Mouzon Jacques, Chambers Georgina M, Zegers Hochschild Fernando, Mansour Ragaa, et al. (2018) International Committee for Monitoring Assisted Reproductive Technology: world report on assisted reproductive technology, 2011. Fertil Steril 110(6): 10671080

52. Andersen AN, Goossens V, Ferraretti AP, Bhattacharya S, Felberbaum R, et al. (2008) Assisted reproductive technology in Europe, 2004: results generated from European registers by ESHRE. Hum Reprod 23(4): 756771.

53. Ferraretti AP, Goossens V, Kupka M, Bhattacharya S, De Mouzon J, et al. (2013) European IVF-monitoring Consortium, European Society of Human Reproduction, Embryology. Assisted reproductive technology in Europe, 2009: results generated from European registers by ESHRE. Hum Reprod 28(9): 2318-2331.

54. Kupka MS, Ferraretti AP, de Mouzon J, Erb K, D’Hooghe T, et al. (2014) European IVF-monitoring Consortium, European Society of Human Reproduction, Embryology. Assisted reproductive technology in Europe, 2010: results generated from European registers by ESHRE. Hum Reprod 29(10): 2099-2113.
55. Kupka MS, D’Hooghe T, Ferraretti AP, De Mouzon J, Erb K, et al. (2016) European IVF-monitoring Consortium, European Society of Human Reproduction, Embryology. Assisted reproductive technology in Europe, 2011: results generated from European registers by ESHRE. Hum Reprod 31(2): 233-248

56. Calhaz Jorge C, De Geyter C, Kupka MS, De Mouzon J, Erb K, et al. (2016) European IVF-monitoring Consortium, European Society of Human Reproduction, Embryology. Assisted reproductive technology in Europe, 2012: results generated from European registers by ESHRE. Hum Reprod 31(8): 1638-1652.

57. Calhaz Jorge C, De Geyter C, Kupka MS, de Mouzon J, Erb K, et al. (2017) European IVF-monitoring Consortium, European Society of Human Reproduction, Embryology. Assisted reproductive technology in Europe, 2013: results generated from European registers by ESHRE. Hum Reprod, Oxford University Press 0268-1161.

58. Gunby J, Bissonnette F, Librach C, Cowan L (2010) Assisted reproductive technologies (ART) in Canada: 2006 results from the Canadian ART Register. Fertil Steril 93(7): 2189-2201.

59. Gunby J, Bissonnette F, Librach C, Cowan L (2008) Assisted reproductive technologies (ART) in Canada: 2004 results from the Canadian ART Register. Fertil Steril 89(5): 1123-1132.

60. Gunby J, Bissonnette F, Librach C, Cowan L (2009) Assisted reproductive technologies in Canada: 2005 results from the Canadian Assisted Reproductive Technologies Register. Fertil Steril 91(5): 1721-1730.

61. Gunby J, Daya S (2007) Assisted reproductive technologies (ART) in Canada: 2003 results from the Canadian ART Register. Fertil Steril 88(3): 550-559.

62. Zegers Hochschild F, Schwarze JE, Crosby JA, Musri C, Urbina MT (2016) Assisted reproductive techniques in Latin America: the Latin American Registry, 2013. Reproductive BioMedicine Online 32(6): 614-625.

63. Zegers Hochschild F, Schwarze JE, Crosby J, Musri C, Urbina MT (2017) Assisted reproduction techniques in Latin America: the Latin American Registry, 2014. Reproductive BioMedicine Online 35(3): 287-295.

64. Zegers Hochschild F, Schwarze JE, Crosby J, Musri C, Urbina MT (2018) Assisted reproductive techniques in Latin America: the Latin American Registry, 2015. Reproductive BioMedicine Online 37(6): 685-692.

65. Zegers Hochschild F, Schwarze JE, Crosby JA, Musri C, do Carmo Borges de Souza M (2015) Assisted Reproductive technologies in Latin America: the Latin American Registry, 2012. Reproductive BioMedicine Online $30(1): 43-51$ 